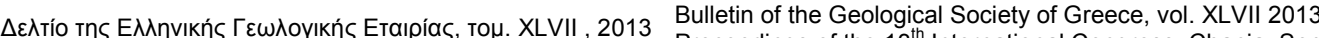
Xroceedings of the $13^{\text {th }}$ International Congress, Chania, Sept.

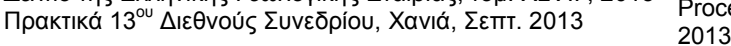

\title{
APPLICABILITY OF THE "LEFKA ORI" WESTERN CRETE REGION GEOFACTORS' INTERACTION MATRIX (GFIM) AS A KEY TO UNDERSTANDING THE ENGINEERING GEOLOGICAL CONDITIONS
}

\author{
Pavlaki A. ${ }^{1}$, Meladiotis $\mathrm{I}^{2}$ and Pavlakis P. ${ }^{3}$ \\ ${ }^{1}$ Geologist, PhD-Civil Engineering Department AUTH. "Consulting Engineering Bureau of Geological \\ Researches \& Studies”, 56 Tzanakaki Str, Chania, Greece, catrpaul@otenet.gr,ppavlakis@tellas.gr \\ ${ }^{2}$ Professor, Aristotle University of Thessaloniki, Department of Civil Engineering, Laboratory of \\ Engineering Geology, 54124 Thessaloniki, Greece, imeladiotis@yahoo.gr \\ ${ }^{3}$ Civil Engineer, PhD-Civil Engineering Department AUTh. “Consulting Engineering Bureau”, 56 \\ TzanakakiStr, Chania, Greece, ppavlakis@tellas.gr
}

\begin{abstract}
The results of extensive and long-lasting investigations on various geofactors in the "Lefka Ori - Chania" W.Crete region revealed the major role of their interaction in the engineering geological conditions' formation. The investigated region has a specific scientific interest due to its admirable geoenvironment which is governed by an active geodynamic regime and affects the active development of all the geofactors. It also shows a rapid growth, which evolves into a fragile balance with the valuable geoenvironment thus the vision of its aeiforos development in the future, needs, among others, the wide recognition of its engineering geological conditions. The methodology was based on multidisciplinary and thorough research studies utilizing qualitative \& quantitative analysis of various geofactors. The results, which are depicted on new geothematic maps, prove that these geofactors are the product of parallel progressive and interactive evolutions in an environment dominated by an active geodynamic regime, where the corresponding stress field affects in a catalytic way to many geo-developments. Besides this, a great number of striking geo-structures have been revealed, characterizing the investigated area of "Lefka Ori - Chania", as a globally unique Natural Geological Laboratory. The GeoFactors' Interaction is represented graphically on a Matrix form creation, called then "Lefka Ori Western Crete GFIM". This matrix can serve us, as a useful scientific tool, for the investigated area's engineering geological conditions' recognition and we propose its application to relevant research studies.
\end{abstract}

Key words: Lefka Ori -Chania, aeiforos development, geofactors' interaction, active regime.

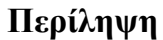

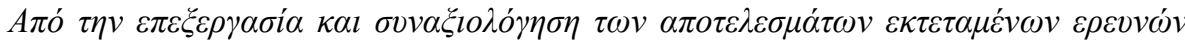

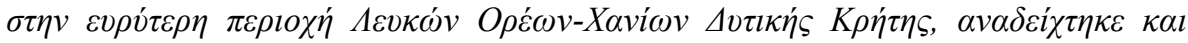

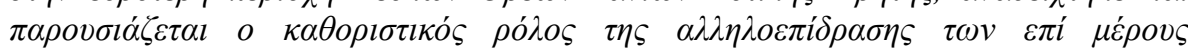

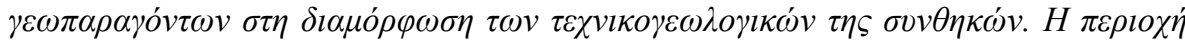

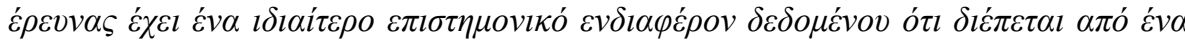

$\underline{\text { XLVII, No } 3-1820}$ 


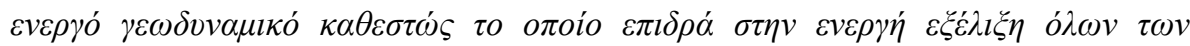

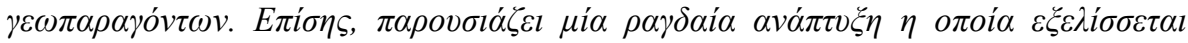

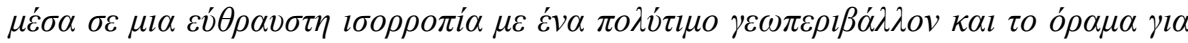

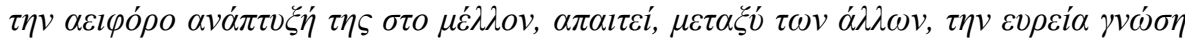

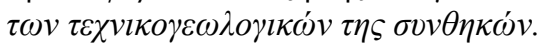

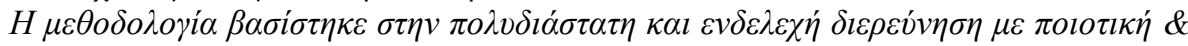

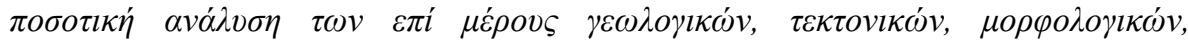

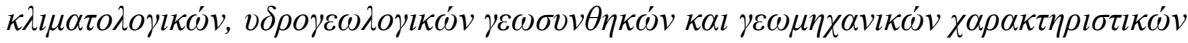

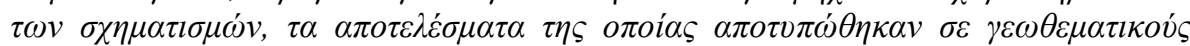

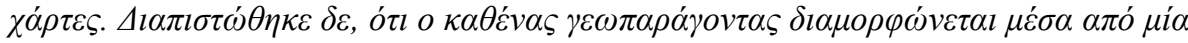

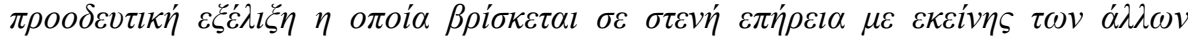

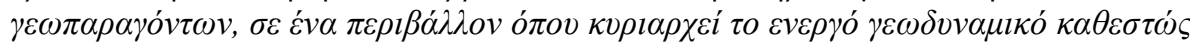

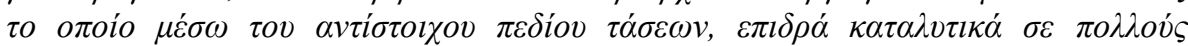

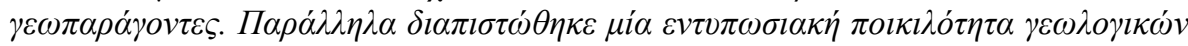

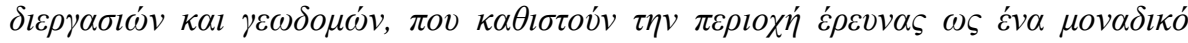

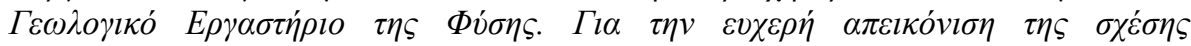

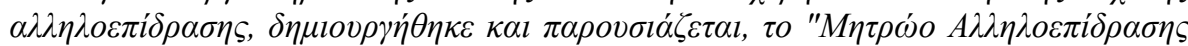

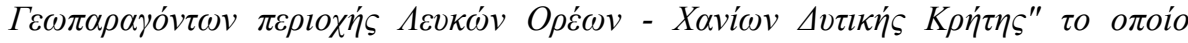

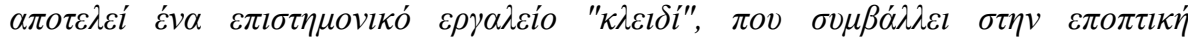

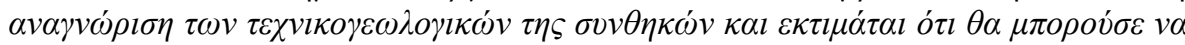

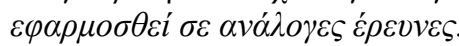

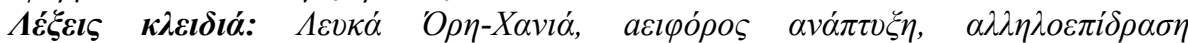

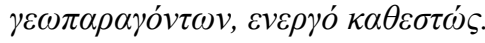

\section{Introduction}

Engineering Geology is a relatively new field of earth sciences and very important as well, especially in today's era of rapid urban growth and development planning associated with major infrastructure projects. The engineering geologic conditions of a region formed by the interacting geofactors relative to geology, tectonic, seismotectonic, climate, morphology, hydrogeology and geomechanical properties of materials, which predetermine the engineering geological response which may arise from influences derived from endogenous \& exogenous natural processes and human activities (Pavlaki, 2006). Based on this consideration and in the context of an integrated \& efficient investigation of the engineering geologic conditions of the region under study, we investigated all the above geofactors, with emphasis on their interaction. The investigated region lies in the west part of Crete (Figure 1); the largest and the most southern Hellenic island which as it is located on the Eastern Mediterranean Sea's centre, holds a key-position with great geoscientist and geopolitical importance.

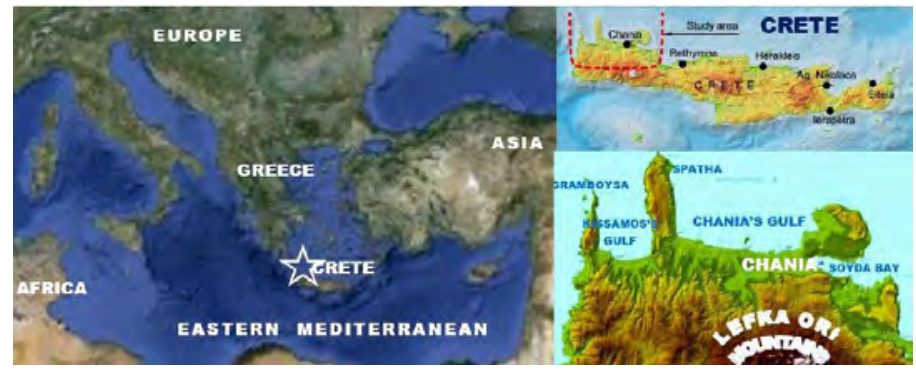

Figure 1 - The investigated region of "Lefka Ori" (+2,452 m) - "Chania" in western Crete.

The surrounding area has always drawn international geoscientific interest due to its rich geological history characterized, as mentioned in numerous published works, by strong geodynamic processes \& changes, including oceanic creations, continental collisions, orogenesis

$\underline{\text { XLVII, No } 3 \text { - } 1821}$ 
(Figure 2). The geological structure of Crete is represented by an accumulated nappes' pile which was developed during Jurassic to Miocene, within the Alpine Orogenesis, under a general compression regime closely connected to plates' convergence (Kilias et al. 1994). From Tertiary until recently, the geodynamic regime is represented by the Eurasian and African plates' convergence, which evolves through a roll-back mechanism causing the southward migration of the convergence's limit until the present position which lies along the middle zone of Eastern Mediterranean (Papazachos \& Papazachou 2003, Ten Veen \& Kleinspehn 2003). The migration of the convergence's limit is evolving through complex operations which have impacted the geologic \& tectonic setting of the surrounding region. Moreover these processes especially the corresponding stress field, affect in a direct or an indirect way, the individual geofactors' formation (Pavlaki, 2006), resulting in the region's geoenvironment which is characterized by an unprecedented diversity of geomorphological features which make it unique.

In the central and southern part of the study area, the spectacular "Lefka Ori" Mountains $(+2,452 \mathrm{~m})$ dominates, which represents a great tectonic window created under strong uplifting processes, associated by the extensional exhumation of the lower tectonic nappes. The mountains are constructed from carbonated and fractured rocks, the lithology of which in combination with the tectonic processes (especially the uplift) and the high rainfall as well, have contributed to the wide karstic development. The karstification of the mountains results in an impressive variety of karstic geostructures, including caves, potholes, gorges, plateaus and major aquifers. The latter transports large quantities of groundwater which flows to the surface through springs and into the sea via submarine groundwater discharge (Pavlakis, 1989, Meladiotis et al., 1993, Pavlaki, 2006).

In the central-northern part of the study region, a different landscape is formed, represented by the Chania - Souda tectonic basin. This is bound by neotectonic normal faults, which were generated progressively from Miocene to present under a general extensional regime (Mountrakis, Kilias, et al., 2012, Pavlaki, 2006). That period, the Neocene sediments were progressively deposited in the basin as well. This area is now covered by bountiful vegetation and cultivated land. The northern and western parts of the study's region, including the gulfs of Chania and Kissamos and the capes of Spatha and Grambousa (Figure 1), are very famous for their beautiful shores and constitute a major attraction for the residents and visitors alike. Furthermore, these coasts are known for their endless sandy beaches and picturesque rocky bays which record the neotectonic evolution. These are shown on the coastlines' lifting and on the well preserved faults' coastal surfaces.

The residential development is linked to the expansion of settlements in the northern zone $(149,100$ inhabitants), clustering in the city of Chania, which is comprised of the old and new town, reflecting a diverse architectural influence \& cultural history (e.g. Venetian, Muslim, neoclassic, modern). The tourism development is significant with a capacity of 55,300 beds. Moreover, in the northern part of the Regional Unit of Chania most of the main infrastructure projects have been planned and constructed, such as, the National Road along the northern coastline which connects the city of Chania to the rest of Crete, the Chania Airport, the Port of Souda, the large Project of the Water Resources' Management for Irrigations and Water Supplies of the W. Crete Region, the Waste Water Treatment Plants etc.

The valuable geoenvironment, the precious natural environment which involves a huge amount of valuable endemic species, the favourable climatic conditions and the significant cultural heritage, make up the comparative advantages of the Lefka Ori - Chania region (Regional Unit of Chania, Prefecture of Crete). It is noted that this area, like the rest of the island of Crete, freed recently (in the early 20th century) by Eleftherios Venizelos, after centuries of enslavement and many revolutions. Today, in the framework of its development, is trying to exploit its comparative advantage, as it aspires to become an important cultural and tourist Eastern Mediterranean's hub. Nevertheless, the rapid growth at an undoubtedly active and complex geoenvironment, led, in some cases, to uncontrolled interventions on the environment, which caused adverse effects such as degradation, significant alterations and failures' events. Considering all the foregoing we

$\underline{\text { XLVII, No } 3 \text { - } 1822}$ 
appreciated the necessity for engineering geological knowledge and we proceeded to the preparation of this survey without any financial support, but having the deep belief that it can contributes to the vision of an "aeiforos development" for the region's future.

[We propose using the Hellenic word "AEIFOROS", which begins with the first \& most powerful letter of the Hellenic alphabet: A and in contrast to the word "sustainable" where the concept has been defined, the Hellenic word has itself the original \& comprehensive meaning (AEI=always, Foros=who has and brings, produces). It also includes the sense of upgrading. Beside this, it is noted that in the Hellenic alphabet, the letters' symbolism and the words' formation are not random but they include the conceptual meaning \& blessing, thus the Hellenic language is considered ideal, the great feeder of all languages.. Ex: the letter A means the beginning under the initial sunlight's force].

The purposes \& scopes of this work's preparation were: 1. Contributing to the science, due to the scientific interest which arises from the individual geofactors' investigation in a rapidly developing area, governed by an active regime. 2. Contributing to the study's region development projects' \& human activities' rational planning, by providing support through; the engineering geologic knowledge, the identification of geological hazards and the determination of the uncontrolled human interventions that cause alterations and failures' events. 3. Contributing to the protection, enhancement \& rational use of the study's area geoenvironment which represents a valuable Geological Laboratory of Nature, thus to give it unharmed to future generations.

\section{Methodology}

This paper focuses on evaluating the results derived from qualitative \& quantitative analysis of individual geofactors relative to geology, tectonic, geomorphology, hydrogeology, climate, hydrogeology and geomechanical properties of materials, with emphasis on their interaction in the engineering geological conditions which formed in the survey's region. The course of the investigations was extensive and required a multidisciplinary scientific research which included:

- The collection, processing and evaluation of primary data, of the various research data (geophysical, boreholes), of the existing geothematic maps \& bibliographic data relevant to the object and the area of research, but also relevant to the methods' applied in other analogous regions (more than 1,000 works were collected). In addition, the surveys included the concentration and using of scientific data, which refer to colour aerial photos, orthophotos, thermal images, satellite images (Landsat 5, Spot 2).

- The realization of extensive field research which lasted 18 years and had as main subject: 1. The investigation \& registration of many geological characteristics in the framework of the geothematic maps' preparation (contacts, beddings, faults, discontinuities etc). Moreover, the definition, analysis and interpretation of various geomorphological processes and structures which make the investigated area a complete Natural Geological Laboratory (karstic formations, gorges, uplifting coastlines etc). 2. The quantification of the coefficient $\mathrm{K}$ of the geological formations' permeability, by performing pumping tests in water drillings and by measuring the geometric features of the discontinuities in many locations in the context of the "Killary's" method. 3. The investigation regarding the rockmass qualitative condition, by utilizing the macroscopic observation and recording the features relevant to the structure, the discontinuities' surfaces and the weathering degree. 4. The quantitative analysis of the geological formations' geomechanical properties based on the results of extensive works (field \& laboratory). 5. The determination of the intentional and unintentional human impacts that cause adverse effects on the geoenvironment.

In order to create a graphical representation of the geofactors' interaction, we used "Hudson's first Matrix" (1992) as a framework and in addition we expanded its implementation to the engineering geological conditions existing in an extensive region. This led to the creation of the "Lefka Ori" Western Crete GFIM (GeoFactors Interaction Matrix).

$\underline{\text { XLVII, No } 3 \text { - } 1823}$ 


\section{Geofactors}

\subsection{Geodynamic Processes}

The geological history of the surrounding Mediterranean Region is characterized by strong geodynamic processes. Some of them influenced the study's area geologic creation, which is closely connected with the old basins' evolution, the Alpine orogenesis and the modern geodynamic regime represented by the Eurasian and African plates' convergence. The Mediterranean's geodynamic evolution is reflected in its corresponding paleogeographic evolution, highlights of which are attributed to the paleogeographic maps of Figure 2-a (Scotesse et al, 1998). The progressive location of Crete's geoenvironment is relatively determined (indicating by red symbols), based on the multi-geological criteria's evaluation (Pavlaki, 2006).

From Oligocene until now, the dominant process is the African and Eurasian plates' convergence, evolving via the subduction of the African lithosphere under the Aegean plate. The subduction is characterised by a southwards progressive retreating (Figure 2b), through a roll-back mechanism, accompanied by the southward Aegean plate's expansion as well (Mountrakis, 2001, Papazachos \& Papazachou, 2003, Ten Veen \& Kleinspehn 2003). This geodynamic retreat has affected the corresponding migration of a "double system" stress field, characterised by the development of compression regime in every convergence's boundary and of the corresponding extension in the relative inner (Kilias 2001). This represents the controlling factor which influenced the geologic \& tectonic evolution of the study area. Particularly, the southward migration of the convergence's limit from the earlier Crete's position to its recent position in the middle of E. Mediterranean (Mediterranean Ridge), was associated by the corresponding southward compression's migration, which dominates today in the M.R. Zone (Figure 3). In the internal region (back-arc basin, Crete), the initial compression was followed, from Miocene until now, by an extensional regime which induced the extensional exhumation of the lower tectonic nappes of Crete, resulting in the tectonic windows' generation.

Today, the convergence is characterized by strong active processes, represented on the map of Figure 3 (from Pavlaki, 2006. The map, as mentioned in that work, was prepared according to the evaluation of geodetic, tectonic and seismotectonic data, obtained from many published papers). As it is clearly shown on Figure 3, the recent geodynamic regime can be described as a counterclockwise continuously compounded plates system shift, including Arabian, Anatolian and Aegean plates, which under successively pushing movements, through progressively increasing speeds, reached the maximum velocity of $\sim 3.9 \mathrm{~cm} / \mathrm{yr}$ in the $\mathrm{SW}$ part of the Aegean plate (the location of the study area), which thrusts on the African plate. The latter is moving northwards at a velocity of $\sim 1 \mathrm{~cm} / \mathrm{yr}$ and is subducting amphitheatrically beneath the Aegean plate in Crete region, as it was initially detected from Papazachos \& Comninakis 1970, via the Benioff zone's definition. At present, the movements that have been recorded in the investigated area, show SW direction and velocities up to $\sim 3,9 \mathrm{~cm} / \mathrm{y}$, which are of the highest ever been registered in the Hellenic arc (Pavlaki, 2006). The crust under west Crete consists of a continental top layer of 15 $20 \mathrm{~km}$ thickness above a $20-30 \mathrm{~km}$ thick subducting fossil accretionary wedge with a characteristic an echelon fault sequence, while the downgoing Moho lies at a depth of 40-60 km (Knapmeyer \& Harjes, 2000). The pushing of the subducting African plate in combination with the accretionary wedge's formation beneath west Crete is considered to have contributed to the strong uplift which is observed on the study area (Pavlaki, 2006).

The plates' convergence, especially the subduction of the African lithosphere beneath the Aegean has affected the strong active deformation of the surrounding area and the Hellenic arc formation. Moreover, the strong compression in the recent convergence's zone has resulted in the generation of the "Mediterranean Ridge", a great Accretionary Prism which extends south of Crete (Figure 3 ). This is the fastest outward growing wedge in most recent Earth history. The rate of accretion is mirrored by enormous average outward growth rates of the M.R. up to $17.7 \mathrm{~km} / \mathrm{my}$ which makes it the fastest growing wedge known on earth (Kopf et al, 2003).

XLVII, No 3 - 1824 
The intense geodynamic evolution and the corresponding stress field development have had the decisive impact on the study's area geological creation and on its active deformation associated with the faults' activation and the strong seismic activity.

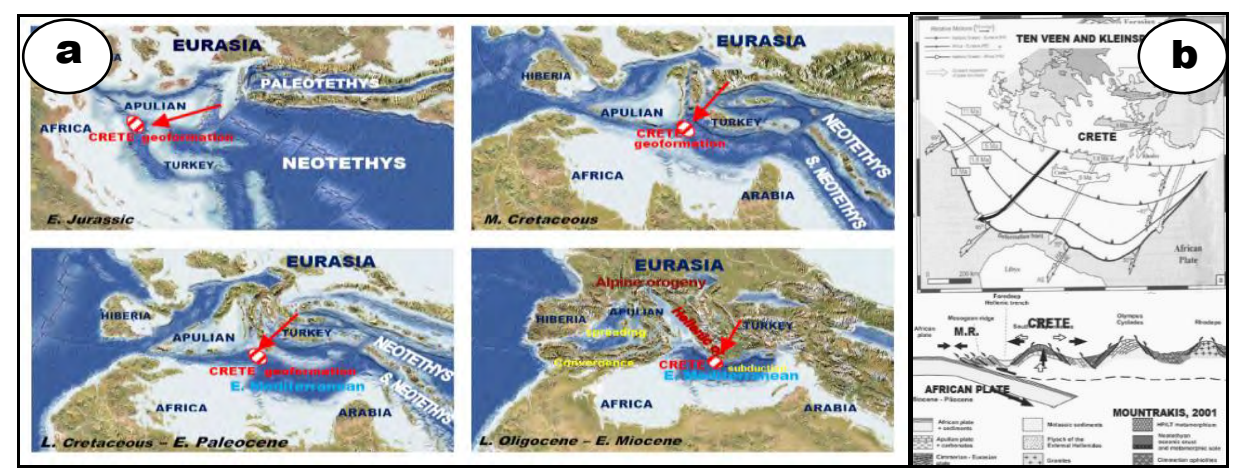

Figure 2 -a) The Mediterranean's paleogeographic evolution (Scotesse et al, 1998), whereas is depicted the progressive position of Crete's geoenvironment (Pavlaki, 2006). b) The southward migration of the convergence's limit since Miocene (Ten Veen \& Kleinspehn, 2003), which gave rise to the corresponding orogenesis (Mountrakis, 2001).

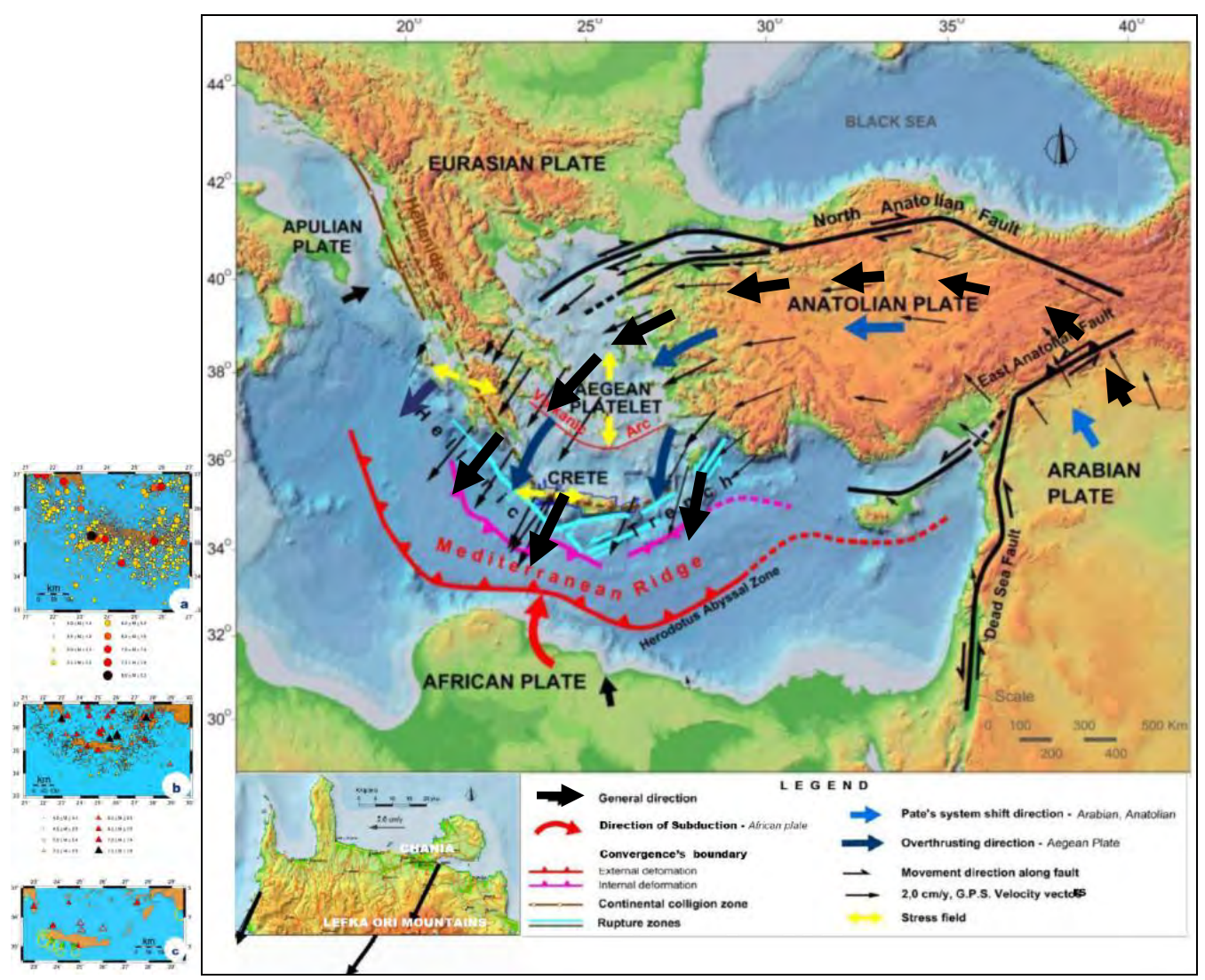

Figure 3 - The Geodynamic Regime of the surrounding Region of Crete (Pavlaki, 2006). The spatial distributions of the earthquakes' epicentres are depicted in maps: (a) shallow earthquakes (b) intermediate-depth earthquakes (c) earthquakes that caused damage (see explanations in $\S 3.2$ ) 


\section{2. Seismicity}

The strong active geodynamic processes, especially the subduction of the eastern Mediterranean lithosphere under the Aegean plate, contributes to the study's area active tectonic deformation, associated with intense seismic activity and strong earthquakes' incurrence $(M>7.5)$. The strongest earthquake known to have been in Mediterranean, had occurred on $365 \mathrm{AD}, \mathrm{M} 8.3$, with an estimated epicentre in the undersea area which lies SW of Crete. The earthquake which was followed by a large tsunami caused widespread damage and intensely natural disasters in the island of Crete and throughout Eastern Mediterranean (Papazachos \& Papazachou 2003).

The qualitative assessment of the surrounding area's seismicity is represented on the maps of Fing.3, in which, the spatial distribution of the earthquakes' epicentres are depicted; shallow earthquakes (3-a), intermediate-depth earthquakes (3-b) (Pavlaki, 2006). The data cover the period 550BC - 2003AD and have been obtained from the list of Geophysics, Aristotle University (http:// lemnos.geo.auth.gr). As it is shown the seismic activity the relevant to the shallow earthquakes is important in the sea region which extends SW of west Crete and is closely connected (among others) with three significant undersea faults (Pavlaki 2006). The seismic activity the relevant to the intermediate-depth earthquakes is important in the NE Crete's marine area and is closely connected with the Benioff zone (part of 70-100km depths, Papazachos \& Papazachou 2003).

Moreover, the spatial epicentres' distribution of the AD strong earthquakes that have caused damage in west Crete (Figure 3-c, shallow: circles, intermediate-depth: triangles), indicates that the shallow earthquakes' epicentres present the largest concentration in the marine area which is extended S-SW of west Crete, while the intermediate depths earthquakes' epicentres, concentrate in the N-NE Cretan's sea area. Furthermore, important information about the earthquakes which caused damage in the area are given in the works of Papazachos \& Papazachou, 2003 and of Pavlaki, 2006 as well, in which, data from all historical records of Crete have been concentrated.

The quantitative assessment of seismic hazard in the region is presented in a recently published, specific and detailed research of Mountrakis, Kilias et al., 2012, based on an integrated approach of geological, seismological \& seismotectonic data. This work provides the respective technical design values which are essential to be applied in the survey's region.

\section{3. Genesis of the Natural Geological Laboratory "Lefka Ori - Chania", within the Interactive Evolutions of the Individual Geofactors}

The geological structure of west Crete is very complicated and always attracts the interest of many scientists, who in many cases have reconsidered and revised their views, as it is indicatively shown in many published works and on the geological maps of IGME as well (sheets, Chania, Alikianos, Brusses), which do not fit together. This led to the need of a new geological map's preparation, scale.1:50.000, which was based on the results of extensive and long lasting research. This map is presented in reduced in Figure 4, with the stratigraphic sequence - corresponding photos of all the geological formations. Moreover, indicative results of qualitative \& quantitative analysis of the geofactors relevant to geology, tectonic and geomorphology are represented in reduced as well in the same figure. The order of the representation corresponds to the evolution's order, from bottom upwards (the yellow arrow helps by indicating the sense of the evolution or the sense of influence) and can be described as the following:

The stress fields which were evolved through the progressive geodynamic processes have affected the creation of the study's area geological structure. This is represented as a tectonic pile, which is consisting of different units' tectonic nappes, which were emplaced successively within the Alpine Orogenesis, under a generally compression regime, closely connected with the plates' convergence. During the period of L. Oligocene - E. Miocene, the configuration of the convergence's boundary in Crete area, had caused the culmination of an N-S compression's regime. This affected the extensive thrusts' evolution which was completed with the immersion of the lower nappes as a slab (Kilias et al., 1994), that included the Plattenkalk unit (Pk), the

$\underline{\text { XLVII, No } 3-1826}$ 
Tripalion unit (Trip) and the Phyllites - Quartzites unit (Ph), beneath the upper plate with the upper nappes of Tripolis, Pindos etc (Figure 4, bot). We consider that during this period, in the framework of N-S compression regime, the origin structures of the major F1, F2, F3, F4 zones (and other similar) were generated (Figure 4, geologic map), as frontal, oblique and lateral zones of footwall ramps, in order to enable the extensive thrusting (Pavlaki, 2006). The geometry of their topography is completely compatible with those of the thrust model according to Price \& Cosgrove, 1992 (Figure 4, bot.-cent).

Within the Miocene, the southward migration of the convergence's boundary from the region of Crete to the Eastern Mediterranean's middle zone, led to the development of an N-S extension regime (in Crete region) (Figure2,3,4-bot-right), while at Pliocene-Pleistocene the direction changed to E-W extension (Mountrakis, Kilias et al., 2012). The wide extension, in combination with the pushing of the subducting African plate beneath Crete and the existence of an accretionary wedge beneath west Crete, have contributed to the strong tectonic uplifting (Pavlaki, 2006) and to the uncover of the lower nappes in form of tectonic windows. The largest of these, is the Lefka Ori Mountains, while we have identified a lot of smaller throughout the study area. The most striking of them is the Malaxa tectonic window (Figure 4) which, according to the results of our research, can be represented as an impressive geological \& tectonic miniature of "Lefka Ori' tectonic window.

During all this evolution, the F1, F2, F3, F4 and other similar zones have acted in a catalytic way as precious "articulated levers" that have enabled the huge scale's uplift, resulting in the creation of successive normal faults series (Figure 4), the kinematic of which are the corresponding to the successively evolving stress fields. Such fault zones constitute today the borders of the "Lefka Ori" Mountains and the tectonic basins. The largest of these is the Agia-Chania-Souda basin, where the Neocene \& Quaternary sediments have deposited from Miocene until now.

The faults and all the tectonic discontinuities which have been developed throughout the study area, contribute in a catalytic way to the engineering geological conditions' formation. Thus we proceeded to a detailed investigation regarding the discontinuities, which, according to their evolution and characteristics, can be distinguished, as normal-oblique faults, thrusts-reverse faults and fracture zones represented by long cataclasis. These discontinuities are depicted on a tectonic map sc.1:50.000, presented in miniaturization in Figure 4 (middle).

Moreover, the evaluation of the results derived from the investigations relative to the geological formations, tectonic, morphology and hydrogeology, have revealed the diversification of the geological conditions existing in the study area, that led us to divide it into four sub-geo regions, which are (Tec.map, Figure 4):

\section{The Surrounding "Lefka Ori" Mountains Region}

The mountains are bounded by the F1, F4, E-W trending and F2, F3, N-S trending normal faults (Figure 4, maps, photos). As we have analyzed, their geometry and morphotectonic development indicates that they had been created as deformation structures, during the thrusting events of U.Oligocene -E.Miocene. They have been reactivated in all the subsequent phases, to enable the mountains' uplift, in compatible operating way with the current stress field, acting as normal, oblique normal or tears faults. This consideration is in tune with the results of a detailed study relative to their neotectonic action of Mountrakis, Kilias et al., 2013.

The main mountain constitutes a huge tectonic window of the uncovered lower tectonic nappes, of ( $\mathrm{Pk})$ and (Trip), which are the dominant geological formations of the investigated area. According to the results of our extensive field research, Plattenkalk unit (Pk, Triassic-Eocene), appears being formed, such as in the typical published descriptions, by the development of well bedded, grey-blue, recrystallized limestones (marbles), including thin cherts' intercalations-bulbs. In the upper horizons they have being progressively evolved to thick-bedded marbles with ashgreenish calcisiltites intercalations, culminated at the top in a flysch horizon.

$\underline{\text { XLVII, No } 3-1827}$ 

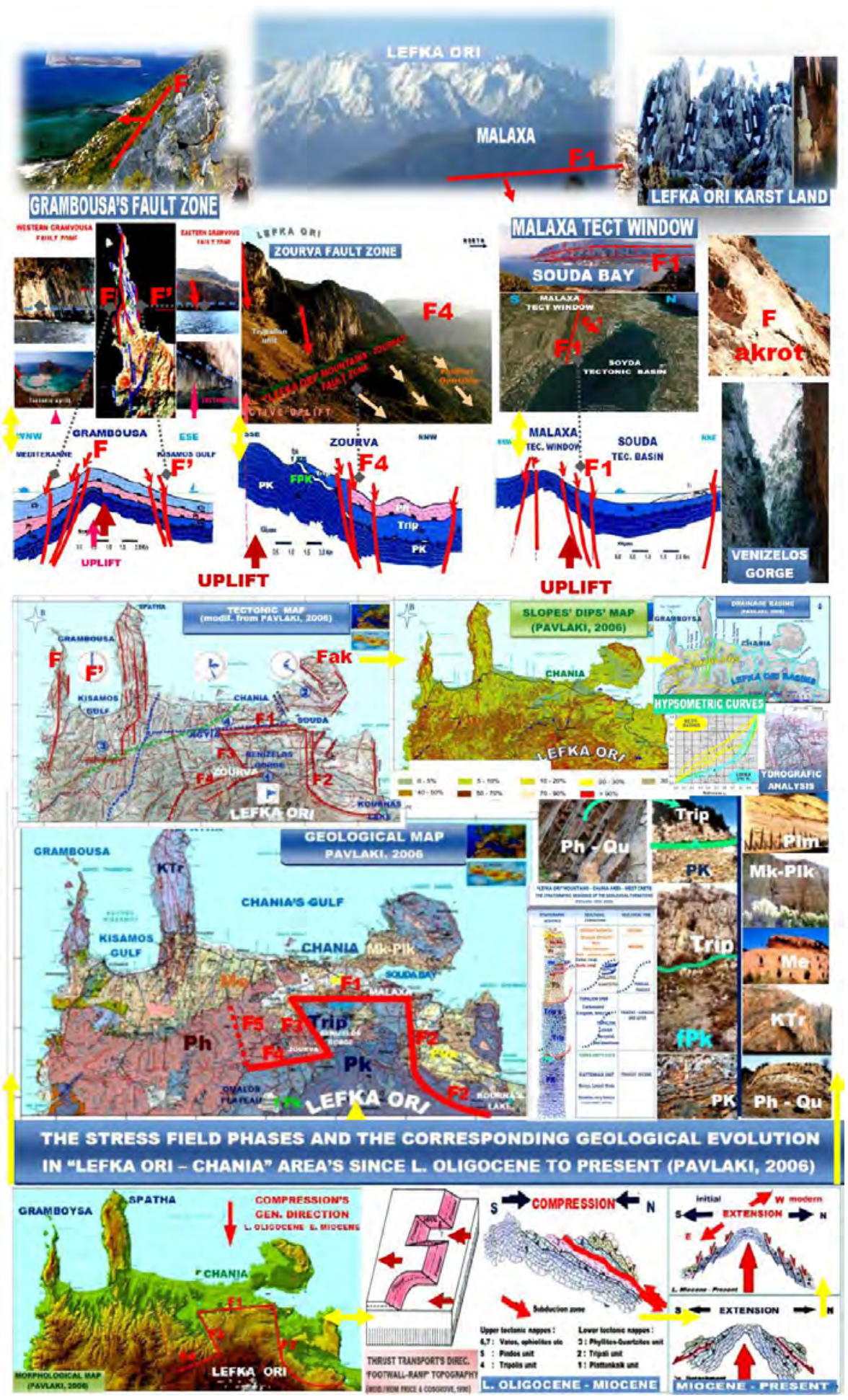

Figure 4 -"Lefka Ori - Chania" West Crete Region: Geological evolution \& recent geology imprinted in: geological simulations, geothematic maps, geological structures corresponding profiles, which represent the geologic generation (From the bottom up wards. The yellow arrow indicates the order of the evolution or influence). 
Flysch, which was identified by Pavlaki, 2006, as the "Lefka Ori -Plattenkalk metaflysch"(fPk), consists of slight metamorphism's calcitic - chloritic fhyllites. It is characterized by thin developments $(\sim 2 \mathrm{~cm}-55 \mathrm{~m})$ and rare appearances (Lefka Ori - Gourgouthes, Omalos, Theriso). We consider that the intense tectonic thinning of flysch and its observed disintegrating behaviour have contributed to its disappearance. In some cases (in the SE area), we have observed intense effects of a strong tectonic compression, reflected in internal thrust slices, shown preferably operate on the thin calcisiltites' surfaces and which bring into contact different Pk horizons.

As we have found, Tripalion unit (Trip, Triassic - later) is clearly thrusting on the PK unit (Figure 4, photos) and includes two different and distinct lithophases (Pavlaki et al 1990, Manoutsoglou, et al., 2001); The lower horizons which resemble those of Pk and which are consisting of well bedded gleaming white -grey marbles, by the difference being, that they have not included cherts. These horizons evolve through lateral lithophases' transitions to the mediumupper and strong tectonised horizons. These consist of thick to unbedded and micro-medium crystalline's carbonate rocks, including white limestones, black dolomites, black cellular dolomites (dol. powder in cells) and carbonated breccia-conglomerate, the pebbles' and breccias' of which, originate from the Pk and lower Trip rocks. Regarding the origin of Tripalion unit, we estimate that it is closely connected with that of Pk unit and probably represents $\mathrm{Pk}$ stratigraphic sections, which during early compressive tectonic stages, have detached from their position and have moved over their own unit (preferably on the plastic behaviour's metaflysch surfaces). These operations, have given rise to intense tectonic development, which led to their fragmentation and reagglutination within various phases. A second possibility is that Trip unit has been formed in an adjacent environment to that of $\mathrm{Pk}$ and within a subsequent compression, was thrusted on it.

The interaction of all these developments resulted in the Lefka Ori formation as huge carbonated massif - tectonic window, which has only a few local interferences of schist or flysch.

The evaluation of the results that derived from our multi factorial survey (field research, geophysical logs, drillings, cores, pumping tests, etc) showed the significant influence of the F1, F2, F3, F4 faults in the engineering geological conditions' formation. The most impressive of them is the spectacular Zourva's fault, which dominates in the northern part of the Lefka Ori Mountains, as part of the $\mathbf{F} 4$ fault zone (Figure 4). Its particular characteristics are: a. The spectacular fault's slickenside formation, associated with the huge displacement of $>200 \mathrm{~m}$. It constitutes the tectonic contact between Trip unit -limestones and Phyllites - Quartzites overthrusting unit $(\mathrm{Ph})$. b. The strong dip faulted slopes and the corresponding steeply inclined strata, associated with the intense failure's events, such as landslides \& rockslides. c. The impressive southern fault-block upthrown, expressed by the huge displacement which contributes to the northern Lefka Ori uplifting and at the same time to the northern fault-block downthrown. This condition has caused the corresponding lowering and northern extension of the carbonated rocks which extend underground beneath the overthrusting $\mathrm{Ph}$ unit, resulting in a catalytic way to the formation of significant underground aquifers.

In the northern part, the significant F1 -Agyia - Malaxa - Souda- fault zone dominates (Figure 4), which is developed by a sequence of normal faults as en echelon trending E-W to ENE-WSW. As we have determine, these faults have contributed to the Malaxa tectonic window formation, especially to the southern fault-block upthrown and to the uncover of the Pk and Trip tectonic nappes and not of Tripolis as it is shown on Igme maps and many published papers as well. Furthermore, these faults have caused the northern fault-block downthrown, resulting in the formation of the Agyia - Souda tectonic basin. They also have affected the Trip-carbonate rocks' underground northern extension, beneath the neocene \& quaternary sediments at depth $20-90 \mathrm{~m}$, as shown the geophysical logo and drilling data. Along parts of this fault zone, a cataclacite formation has been developed up to $50 \mathrm{~m}$ thickness, which, like the rest of the F1 zone contributes to the hydrogeological \& engineering geological conditions' formation. The most impressive of 
all is that the F1 zone, due to its cataclacite, which according to our research is characterized by the average permeability $\mathrm{K}$ of $10^{-9} \mathrm{~m} / \mathrm{sec}$, acts as a valuable natural diaphragm to the underground flows, resulting this way to the discharge of the aquifers and to the Agyia springs' formation.

According to the results of our investigations in Lefka Ori region, the interaction of the geofactors relative to the geological formations, represented by the carbonate rocks' growth, the tectonic, characterised by the significant discontinuities development, the strong tectonic uplift, ( $>5 \mathrm{~mm} / \mathrm{yr}$, Pavlaki, 2006) and the climate as well, have affected the intense Karst development, characterized by extending exokarst and endokarst formations, including a famous variety of karst structures such as pinnacles, dolines, poljes, caves, sinkholes, underground aquifers etc.

2. The Western part of the study region, includes the entire western area and it is characterized by the creation of significant B-N and NE-SW trending normal fault zones, which are considered to be active (in the aforementioned neotectonic study). According to our morphological quantitative analysis, these active fault zones contribute to the regeneration of the western drainage basins and to the western coasts formation as well (photo Grambousa, profile, Figure 4).

3. The Chania's Akrotirion (NE part of the study region) is dominated by long NW - SE trending normal faults, which are characterized by a sequential action. In the centre of this area an extensive surface leveling has been developed.

4. The northern - central part of the study area, includes the Chania - Agia- Souda tectonic basin, in which, the sediments of Neocene and Quaternary have been deposited. In this area, as we have determined, normal faults, which are characterized by small displacements and NNE-SSW \& NW-SE directions, have been developed. The major tectonic structure is the Venizelos NW-SE trending normal fault zone, which contributes to the Chania's eastern tectonic slopes' formation.

Finally, the results of quantitative analysis of all the geofactors throughout the region under survey are given in the geothematic maps \& the representative shapes of Figures $4 \& 5$. The main points which indicate the contribution of the interaction of these geofactors in the individual geological and engineering geologic conditions' formation can be summarized in the following:

1. Following the assessment of the qualitative and quantitative analysis of the morphological relief, drainage basins, hydrographic network and the one of the active faults, a tectonic uplift /erosion mechanism has been identified as the major controlling factor of the geomorphological evolution of the area. The interpretation of the previous data-analysis indicated that the drainage basins are characterized by distinct differentiations relevant to their evolution, according to which they were classified in two main units, the Eastern and the Western one (Figure 4). The Eastern Drainage-Basins "Lefka Ori Mountains (2.454m)" are characterized by a long uplifting history and continuous erosional process at the limestone Mountains which were upfaulted as tectonic horst through successive tectonic uplift episodes. On the other hand, the Western DrainageBasins are younger than the Eastern as the data analysis results have shown and they have been uplifted later. What is impressive is that their formation is linked to the west-ward migration of fault activity towards the active faulting coasts of western-Crete. As the tectonic and hydrographic analyses have shown, the drainage system development reflects the active tectonic deformation.

2. The modern E-W trending stress field contributes to the configuration of many processes \& geostructures, especially to the reactivation of the neotectonic faults, to the N-S trending gorges' formation and to the underground water flows along the N-S compatible faults.

3. Large fault zones influence the formation of strong slope slips associated with failures events, the degradation of rockmass quality and the underground water flows. 


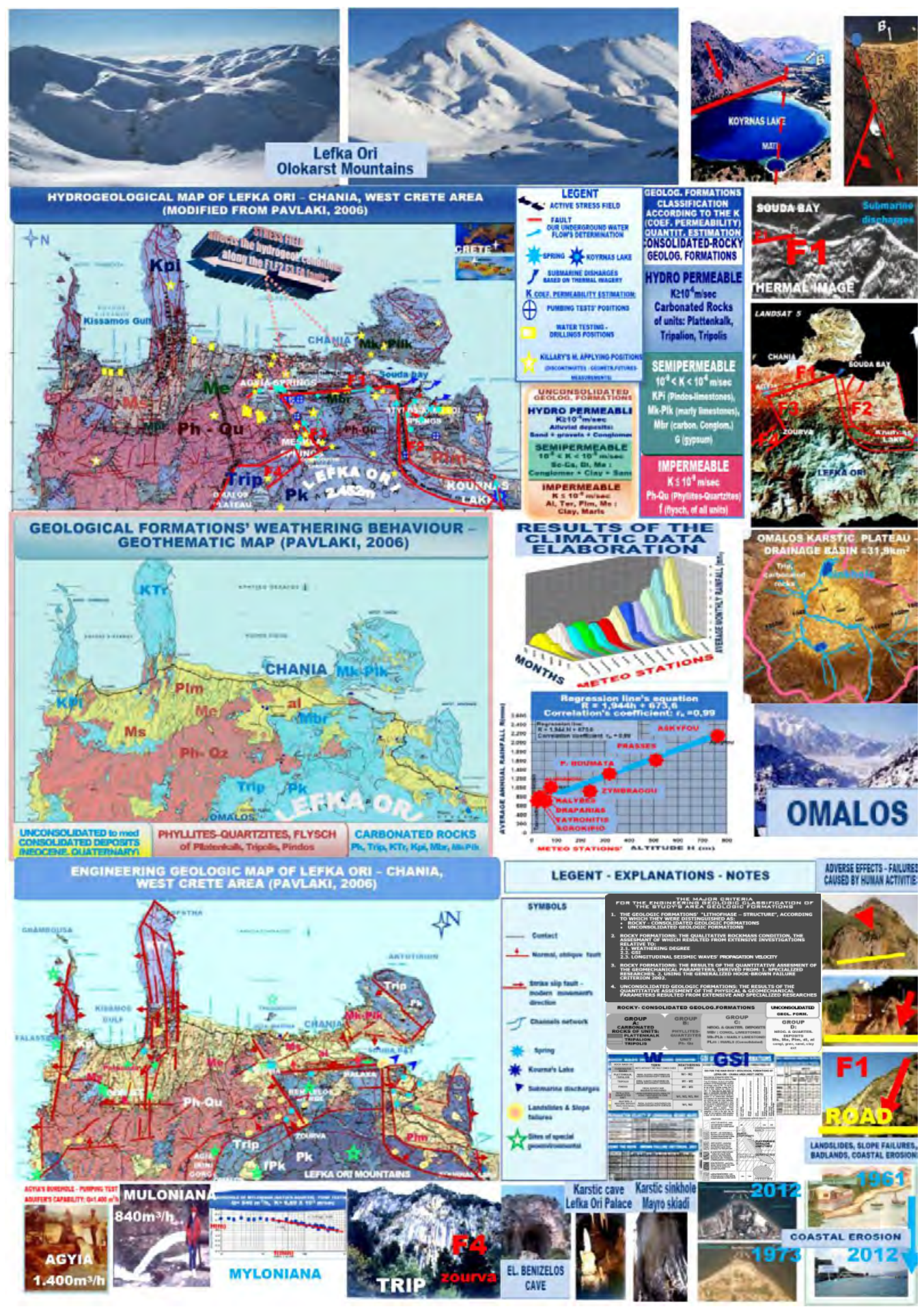

Figure 5 -"Lefka Ori - Chania" Western Crete Region: The results of the qualitative \& quantitative analysis of the individual geofactors relative to hydrogeology, climate, erosion, and geomechanical properties of all the geological formations, depicted in geothematic maps, diagrams and photos. The significant adverse effects by human activities are shown as well. 


\section{Geofactors Interaction Matrix}

In order to create a graphical representation of the geofactors' interaction, we used "Hudson's first Matrix" (1992) as a framework and in addition we expanded its implementation to the engineering geological conditions existing in an extensive region. This led to the creation of the "Lefka Ori" Western Crete GFIM (GeoFactors Interaction Matrix), which is presented in Figure 6. In this matrix where the main geofactors have been defined (1-8), the impacts \& the corresponding effects of each geofactor are described.

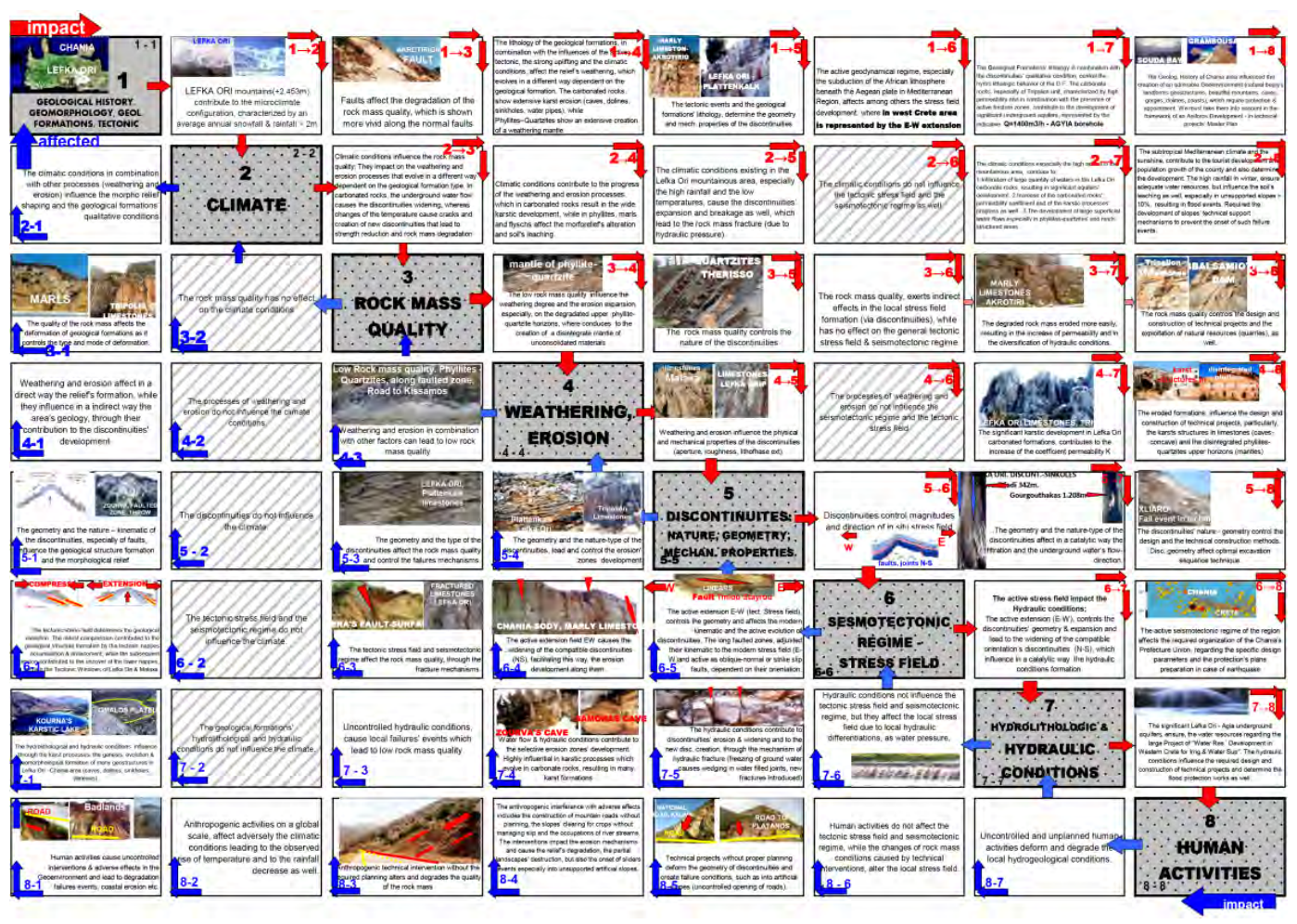

Figure 6- The Geofactors Interaction Matrix of the Lefka Ori - Chania Geoenvironment, based on the "the Hudson's first Matrix" (1992), by expanded and adapted its implementation to the engineering geological conditions existing in the investigated area.

\section{Conclusions}

The results of extensive and long-lasting investigations on various geofactors in the "Lefka Ori Chania" W.Crete region revealed the major role of their interaction in the engineering geological conditions' formation. They also prove that these geofactors are the product of parallel progressive and interactive evolutions in an environment dominated by an active geodynamic regime, where the corresponding stress field affects in a catalytic way to many geo-developments.

Besides this, a great number of striking geo-structures have been revealed, characterizing the investigated area of "Lefka Ori - Chania", as a globally unique Natural Geological Laboratory.

The GeoFactors' Interaction is represented graphically on a Matrix form creation, called then "Lefka Ori Western Crete GFIM", which can serve us, as a useful scientific tool, for the investigated area's engineering geological conditions' recognition. 


\section{Acknowledgments}

The work described in this paper is the product of a long series of investigations that have been self-funded. We thank Prof. A. Kilias and D. Mountrakis for their reviews as well as for their ongoing mentorship both professionally \& scientifically throughout the years.

We heartfelt thank Rebecca Pavlaki for her relentless support throughout the years, because without her precious assistance this work would have never been realized. Moreover we want to heartfelt thank Pauline Goumenaki for her valuable support and Gina Pavlaki for her significant assistance. We would like to thank Mr. Manoutsoglou for his significant support \& enduring patience. Also we would like to thank Terry Stratoudakis for his precious support. We thank $\mathbf{C h}$.

Riziotis and J. Antonopoulos for their helpful scientific discussion throughout the years.

\section{References}

Hudson J.A., 1992. Rock engineering systems. Theory \& Practice. E. Horwood, Great Britain p185.

Kilias A., Fassoulas Ch. and Mountrakis D. 1994. Tertiary extension of continental crust and uplift of Psiloritis metamorphic core complex, in the central part of the Hellenic arc (Crete, Greece, Geol. Rdsch, 83, 417-430.

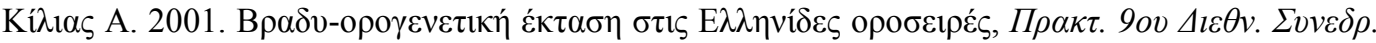

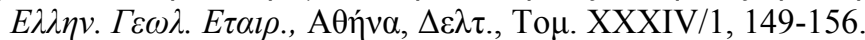

Knapmeyer M. and Harjes H-P. 2000. Imaging crystal discontinuities and the down going slab beneath western Crete, Geophys. J. Int., 143, 1-21.

Kopf A., Mascle J. and Klaeschen D. 2003. The Mediterranean Ridge: A mass balance across the fastest growing accretionary complex on Earth, Journal of Geophys. Research, Vol. 108, No B8, 2372, doi:10.1029/2001JB000473.

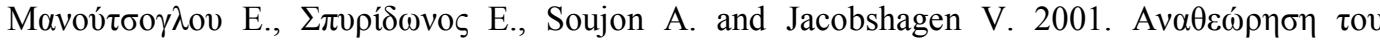

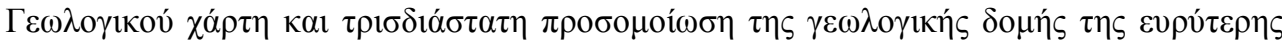

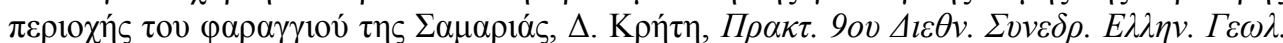

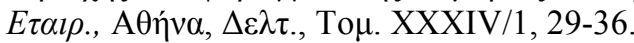

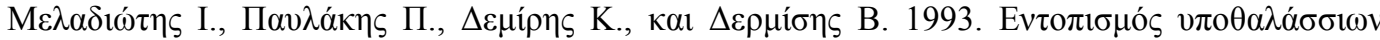

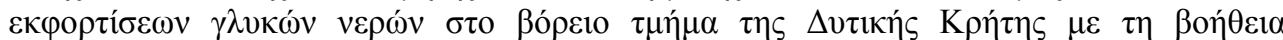



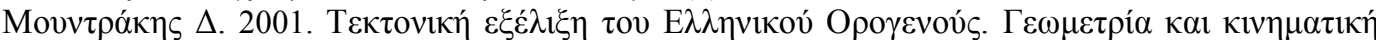

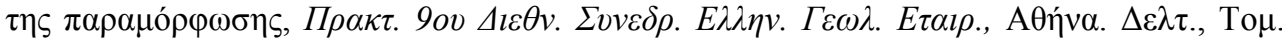
XXXIV/6, 2113-2126.

Mountrakis D., Kilias A., Pavlaki Aik., Fassoulas Ch., Thomaidou E., Papazachos C., Papaioannou Ch. and Roumelioti Z. 2012. Neotectonic study of Western Crete and implications for seismic hazard assessment, Journal of the Virtual Explorer, Electronic Edition, ISSN 1441-8142, volume 42, paper 2.

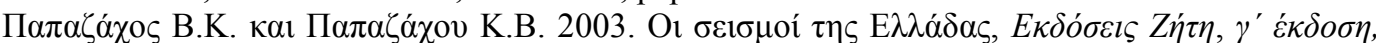



П

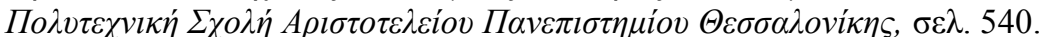

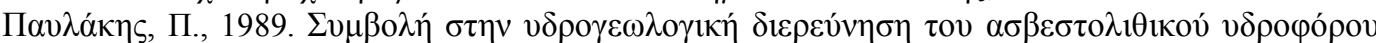

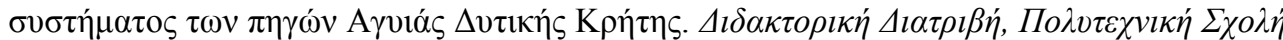

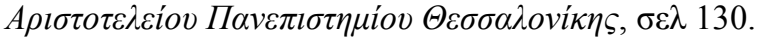

Price N.J. and Gosgrove J.W. 1991. Analysis of Geological Structures, University of Cambridge. Prnt. In Great Britain, Univ. Press, pp 502.

Scotesse C.R. et al. 1998. Sedimentation, Tectonics and Paleogeography of Southern Europe and the Mediterranean Region, availiable at: http://jan.ucc.nau.edu/ rcb7/globaltext.html

Ten Veen J.H. and Kleispehn K.L. 2003. Incipient continental collision and plate-boundary curvature: Late Pliocene -Holocene transtensional Hellenic forearc, Crete, Greece, Journal of the Geological Society, London, Vol. 160, 161-181.



